\title{
Lightweight Design of an Outer Tie Rod for an Electrical Vehicle
}

\author{
Young-Chul Park, ${ }^{1}$ Seung-Kul Baek, ${ }^{1}$ Bu-Kyo Seo, ${ }^{1}$ Jong-Kyu Kim, ${ }^{2}$ and Kwon-Hee Lee ${ }^{1}$ \\ ${ }^{1}$ Department of Mechanical Engineering, Dong-A University, Busan 604-714, Republic of Korea \\ ${ }^{2}$ Central Corporation, Changwon 641-315, Republic of Korea \\ Correspondence should be addressed to Kwon-Hee Lee; leekh@dau.ac.kr
}

Received 24 October 2013; Accepted 6 February 2014; Published 17 April 2014

Academic Editor: Olabisi Falowo

Copyright (C) 2014 Young-Chul Park et al. This is an open access article distributed under the Creative Commons Attribution License, which permits unrestricted use, distribution, and reproduction in any medium, provided the original work is properly cited.

\begin{abstract}
The lightweight design of the outer tie rod installed on an electrical vehicle was achieved through material selection and optimization technique. The aluminum alloy Al6082M was selected as a steel-substitute, and its structural shape was optimized by applying metamodel-based optimization. In this process, finite element analysis was performed to predict the structural responses, such as buckling resistance and fatigue life. First, for an arbitrary base design made of steel, the structural responses were calculated. Then, the design variables were defined to find a lightweight design made of Al6082M. Secondly, metamodel-based optimization based on the kriging interpolation method was applied, leading to determination of an optimum design. The suggested optimum design has the minimum weight satisfying the critical design requirement. Finally, the numerical results of the buckling resistance and fatigue life were validated, through bucking and fatigue tests.
\end{abstract}

\section{Introduction}

The current trend of the structural design of automobile parts is towards lightweight design. Lightweight automobile parts can be developed by selecting steel substitutes, such as aluminum, magnesium, plastic, or composite material, applying manufacturing technology and/or adopting optimization techniques [1-3]. Lower weight requires lower energy consumption. In particular, the realization of lightweight design in electrical vehicles gives rise to an ecofriendly vehicle with high efficiency. The importance of lightweight design in the automotive industry has increased, due to the consistently tightening regulations for protecting the environment $[3,4]$.

There have been many cases of lightweight structural design in body and chassis parts during the past 20 30 years. Among the parts of suspension and steering systems, there have been many cases of lightweight design application for the control arm or knuckle, but there are very few cases for the outer tie rod [5]. This is because the OTR is relatively much lighter than the other parts. However, along with recent trends, car makers and parts manufacturers are interested in lightweight design of the OTR. That is why some parts are developed with their target weight predetermined in units of gram-force during the proto-design stage [3, 5]. Furthermore, consistent lightweight design is an essential means of extending the driving range of electric vehicles [4].

In this study, a lightweight design of the OTR for an electrical vehicle is suggested, by substituting SM45C with Al6082M and applying optimization techniques, considering the buckling and durability performance. The structural responses of buckling and durability are considered in the structural design process of the outer tie rod. Usually, since the buckling is the critical performance, only the buckling is included in the optimization process. Then, after an optimum design is determined, the durability analysis is performed, to investigate whether the suggested design satisfies its criterion.

The most exact method to determine the optimum design is to utilize the sensitivity information of responses and a gradient-based algorithm, since it can provide one design satisfying the K-T necessary condition. In contrast, a metamodel-based optimization method is suitable for problems of structural design requiring much computation time, difficult computational sensitivity problems, or problems having a wavy response function, even though it cannot give the $\mathrm{K}-\mathrm{T}$ point $[3,5]$. The optimization problem of the OTR belongs to this category. Thus, this research 


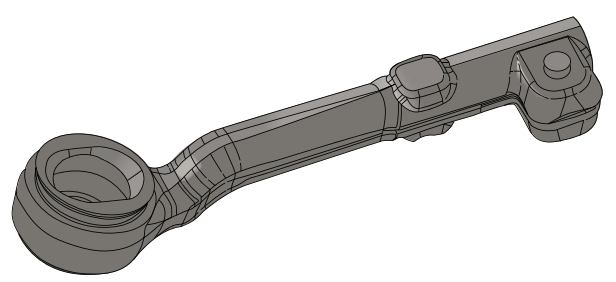

(a) CAD model

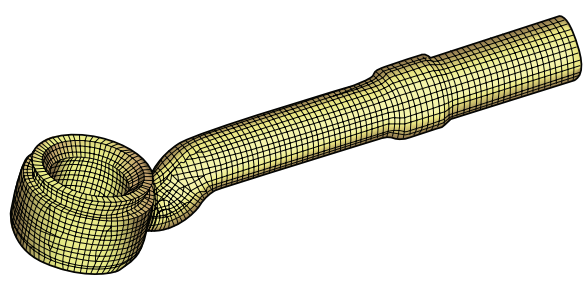

(b) FE model

FIGURE 1: The base model of steel OTR.

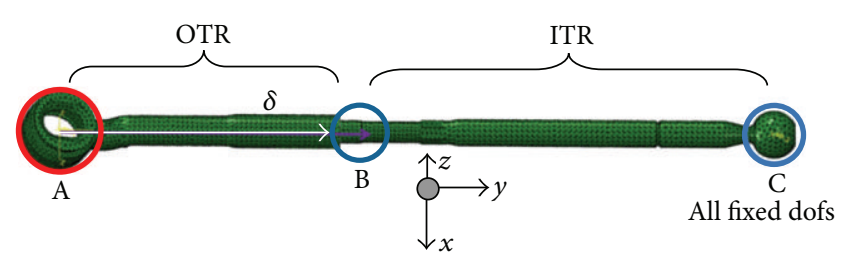

FIgURE 2: Loading condition for buckling analysis.

adopts metamodel-based optimization, to find an optimum design of the OTR. It is known that the kriging metamodel provides accurate predictions of highly nonlinear responses. The design process using the kriging metamodel is as follows $[6,7]$. First, the DOE using Latin hypercube design is carried out, to define the design samples. Second, buckling analysis is performed for as many as the number of sample points. Third, surrogate models of the related responses are built. Thus, the responses of weight and buckling resistance force are replaced by kriging metamodels. It is easy to solve the approximated formulation, since all the responses are replaced by simple mathematical equations. Thus, it is not important to select an algorithm to solve the formulation in this step. As a final step, an optimum design is calculated, by considering formulation. Then, the fatigue life of the suggested optimum design is calculated.

For the validation of the suggested optimum design, buckling and fatigue tests were performed. The design of the OTR was done using CATIA [8], MSC. Nastran [9], and MSC. Fatigue [10] for the durability analysis and Abaqus [11] for the buckling analysis.

\section{Base Design of the Steel OTR}

The OTR is a part that belongs to the steering system changing directions, according to the motion of the steering wheel. Going from steering wheel to steering gear, pitman arm, relay rod, and ITR (inner tie rod), steering power is finally delivered to the wheel through the knuckle after passing through the OTR [5]. The ITR is attached to the OTR and is served as pivot point for the steering gear. The base design of the OTR and its structural analysis were executed for SM45C early on during this car program. However, its material was changed to Al6082M to reduce the weight more. Thus, the structural analysis of the steel OTR was investigated in the early proto-design stage.

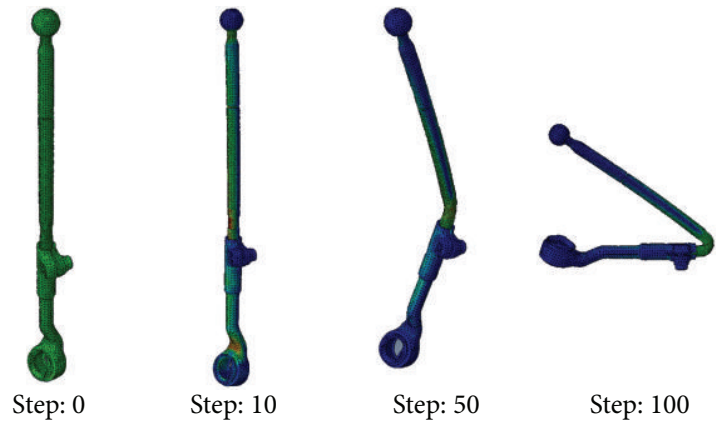

FIGURE 3: Buckling analysis result of steel OTR.

The CAD model and FE model of the initial design are shown in Figure 1. The weight of the steel OTR without bolt and nut was about $378 \mathrm{~g}$. Usually, buckling is the most critical performance in the structural design of an OTR. That is, if the constraint related to buckling is satisfied, the rest of the structural constraints lie in their allowable values. Thus, in this study, only the buckling is included in the optimization process.

The loading condition for buckling analysis is shown as Figure 2. The steel OTR is connected with the ITR at point B. Thus, the buckling analysis was performed in the combined state. The ITR was considered as a predetermined product, since the part manufacturer involved is just responsible for the design of the OTR. A load $\delta$ is applied sequentially on point $\mathrm{A}$ in the $y$ direction, by fixing all degree of freedoms of point $\mathrm{C}$. At that time, the buckling resistance force can be determined. The buckling resistance force is the reaction force of point $\mathrm{C}$, at the moment when the buckling is generated. The result of the buckling analysis is represented in Figure 3. The buckling resistance force of the steel OTR was obtained as $32.6 \mathrm{kN}$, which satisfies the design criterion specified by car maker $\mathrm{A}$.

\section{Structural Optimization of the Aluminum OTR}

3.1. Definition of Design Variable and Optimization Formulation. In general, aluminum has been selected as a steel-substitute material to reduce the weight, since aluminum has almost one-third of the density of steel. In this research, aluminum called Al6082M [3, 5] developed by the part manufacturer was used to replace the steel. However, 


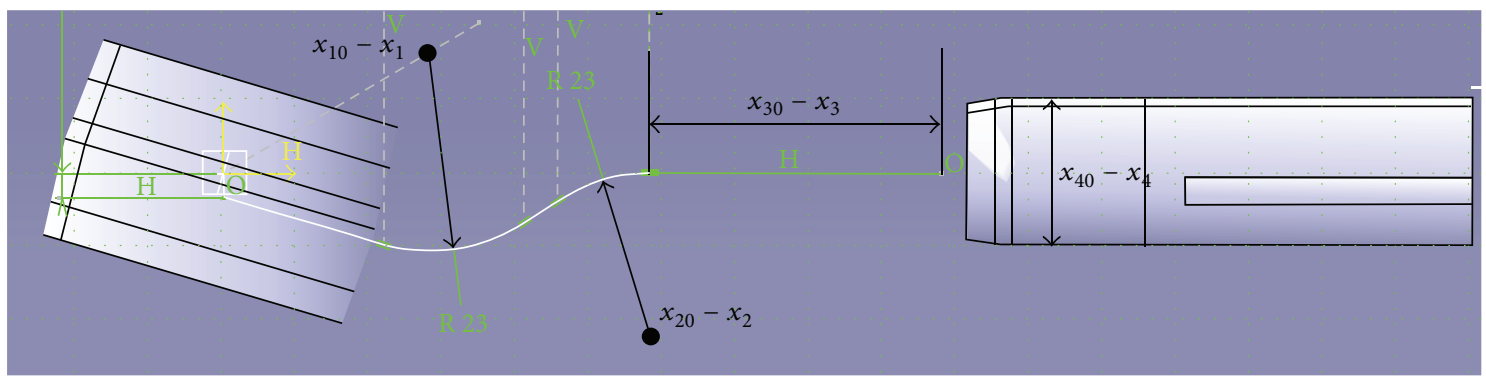

FIGURE 4: Shape design variables.

\begin{tabular}{|c|c|c|c|}
\hline $\begin{array}{c}\text { Definition of shape } \\
\text { design variables }\end{array}$ & $\begin{array}{c}\text { Latin hypercube sampling in } \\
\text { design space }\end{array}$ & $\begin{array}{c}\text { Performing of numerical } \\
\text { simulation }\end{array}$ \\
\cline { 2 - 3 } & Solving of the formulation & $\begin{array}{c}\text { Formulation of approximate } \\
\text { optimization }\end{array}$ & Building of metamodels \\
\hline
\end{tabular}

FIGURE 5: Flow chart for the structural design of Al6082M OTR.

TABLE 1: Material properties of SM45C and Al6082M.

\begin{tabular}{lcc}
\hline Property & SM45C & Al6082M \\
\hline Yield strength $(\mathrm{MPa})$ & 343 & 340 \\
Tensile strength $(\mathrm{MPa})$ & 569 & 380 \\
Young's modulus $(\mathrm{GPa})$ & 210 & 72 \\
Density $\left(\times 10^{-6} \mathrm{~kg} / \mathrm{mm}^{3}\right)$ & 7.85 & 2.71 \\
\hline
\end{tabular}

the strength and stiffness of aluminum have lower values than those of steel for the same structure. Thus, it is necessary to find an optimized shape of the OTR made of Al6082M. The material properties of SM45C and Al6082M are summarized in Table 1.

Based on the modified design of the steel OTR, the design variables defining its shape are represented in Figure 4 . The design variables, $x_{1}$ and $x_{2}$, are related to the shape of its neck, defining the radius curvatures, while the design variables, $x_{3}$ and $x_{4}$, are related to the length and sectional size of the straight part. In Figure 4, the values of $\left[\begin{array}{llll}x_{10} & x_{20} & x_{30} & x_{40}\end{array}\right]^{T}$ are $\left[23^{\circ} 23^{\circ} 58 \mathrm{~mm} 18.5 \mathrm{~mm}\right]^{T}$.

The optimization problem determining its optimum shape can be formulated as

$$
\begin{array}{cl}
\text { Minimize } & W(\mathbf{x}) \\
\text { subject to } & F_{R}(\mathbf{x}) \geq F_{0} \\
& \mathbf{x}_{L} \leq \mathbf{x} \leq \mathbf{x}_{U}
\end{array}
$$

where $\mathbf{x}=\left[\begin{array}{llll}x_{1} & x_{2} & x_{3} & x_{4}\end{array}\right]^{T}, \mathbf{x}_{L}=\left[\begin{array}{llll}0^{\circ} & 0^{\circ} & 0 \mathrm{~mm} 0 \mathrm{~mm}\end{array}\right]^{T}, \mathbf{x}_{U}=$ $\left[9.0^{\circ} 3.0^{\circ} 15.0 \mathrm{~mm} 2.0 \mathrm{~mm}\right]^{T}, W$ is the weight of the aluminum OTR, $F_{R}$ is its buckling load, and $F_{0}$ is the allowable value.

Shape optimization based on the sensitivity information makes the setting of a shape variable difficult and distorts the finite elements in the optimization process $[2,3,5,6]$. In addition, a number of nonlinear analyses are performed in an optimization process to solve (1) (3), and the iterations may not be terminated. Accordingly, it is more realistic that optimization is carried out by replacing the buckling load, $F_{R}$ appearing in (2), with the metamodel. There are methods that generate a surrogate model, such as a response surface model, kriging, a neural network, and others. The present research utilizes the kriging metamodel, suitable for prediction of a highly nonlinear function $[5,6]$. When an approximate model is used, the objective and constraint functions in (1) (2) can be replaced as follows:

$$
\begin{array}{ll}
\text { Minimize } & \widehat{w}(\mathbf{x}) \\
\text { subject to } & \widehat{F_{R}} \geq F_{0},
\end{array}
$$

where $\wedge$ means the metamodel of a response.

The buckling load should be larger than the limit, $25.0 \mathrm{kN}$. However, the allowable value of $F_{0}$ in (5) was set to $27.0 \mathrm{kN}$ to compensate the discrepancy between numerical result and true response.

3.2. Application of Kriging Method to the Aluminum OTR. The flow chart for the structural design of the aluminum OTR is shown as in Figure 5 [7]. First, the DOE (design of experiments) is carried out to define the design samples. As a sampling method, the Latin hypercube design built into Matlab was utilized. In this step, the number of sample points was 50 , which was determined by experience $[2,3,5,6]$. Second, FE analysis using the Abaqus [6] was performed, with a number of sample points. The FE analysis on each row was carried out. The sample points and their responses are summarized in Table 2. Third, the kriging models of the weight and the buckling load were built. Thus, (4) and (5) could be solved by applying the GRG (generalized reduced gradient) algorithm.

In the kriging model, the global approximation model $\widehat{f}(\mathbf{x})$ for a response $f(\mathbf{x})$ is represented as

$$
\widehat{f}(\mathbf{x})=\widehat{\beta}+\mathbf{r}^{T}(\mathbf{x}) \mathbf{R}^{-1}(\mathbf{f}-\widehat{\beta} \mathbf{i}),
$$


TABLE 2: Design of experiments using LHD.

\begin{tabular}{lcccccc}
\hline Exp. number & $x_{1}\left(^{\circ}\right)$ & $x_{2}\left(^{\circ}\right)$ & $x_{3}(\mathrm{~mm})$ & $x_{4}(\mathrm{~mm})$ & $F_{R}(\mathrm{~N})$ & 26,083 \\
\hline 1 & 0.2 & 1.8 & 11.1 & 1.5 & 0.1 & 26,821 \\
2 & 5.4 & 2.0 & 1.9 & 0.2 & 28,825 \\
3 & 7.1 & 1.0 & 5.8 & 0.8 & 26,380 & 143.1 \\
4 & & & $\vdots$ & $\vdots$ & 143.1 \\
$\vdots$ & $\vdots$ & $\vdots$ & $\vdots$ & 0.2 & $\vdots$ \\
49 & 3.5 & 2.3 & 14.0 & 0.9 & 26,429 \\
50 & 1.4 & 1.8 & 5.3 & & 26,961 \\
\hline
\end{tabular}

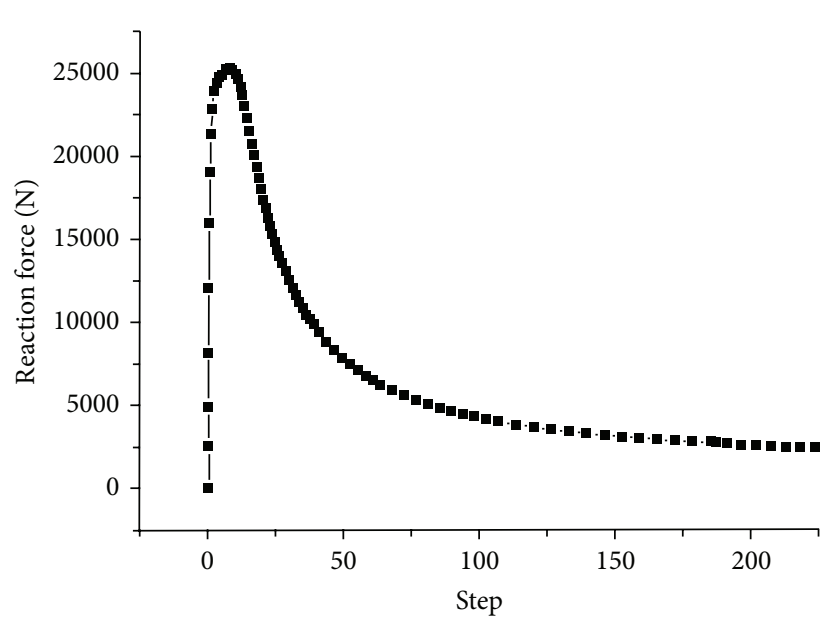

(a) Buckling analysis result

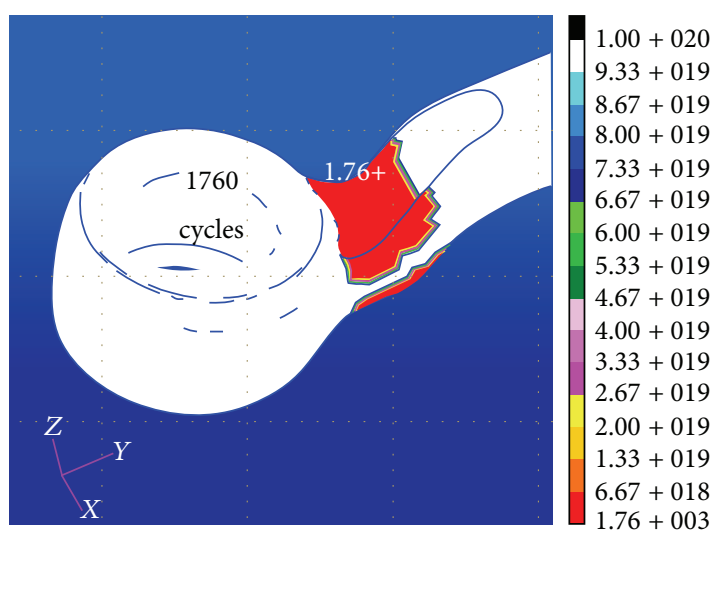

(b) Durability analysis result

FIGURE 6: Buckling and durability analysis result of optimum Al6082M OTR.

where $\mathbf{R}^{-1}$ is the inverse of the correlation matrix $\mathbf{R}, \mathbf{r}$ is the correlation vector, $\mathbf{f}$ is the $n_{s}$ observed data vector, and $\mathbf{i}$ is the unit vector. The correlation matrix and correlation vector are defined as

$$
\begin{gathered}
R\left(\mathbf{x}^{j}, \mathbf{x}^{k}\right)=\operatorname{Exp}\left[-\sum_{i=1}^{n} \theta_{i}\left|x_{i}^{j}-x_{i}^{k}\right|^{2}\right], \\
\left(j=1, \ldots, n_{s}, k=1, \ldots, n_{s}\right), \\
\mathbf{r}(\mathbf{x})=\left[\mathbf{R}\left(\mathbf{x}, \mathbf{x}^{(1)}\right), \mathbf{R}\left(\mathbf{x}, \mathbf{x}^{(2)}\right), \ldots, \mathbf{R}\left(\mathbf{x}, \mathbf{x}^{\left(n_{s}\right)}\right)\right]^{T},
\end{gathered}
$$

where the number of observed data is 50 , and the number of design variables is 4 in this study.

The unknown parameters $\theta_{1}, \theta_{2}, \ldots, \theta_{n}$ are obtained from the following equation:

$$
\text { maximize }-\frac{\left[n_{s} \ln \left(\widehat{\sigma}^{2}\right)+\ln |\mathbf{R}|\right]}{2},
$$

where $\theta_{i}(i=1,2, \ldots, n)>0$. To solve (8), the GRG algorithm built into EXCEL was utilized. The Kriging interpolation method is well explained in $[2,3,12-14]$.

3.3. Optimum Design Result and Durability Analysis. This research utilized an in-house program [3] to solve the optimization problem defined in (3) (5). The optimizer of the in-house program is the GRG method, which is an optimization algorithm built into the EXCEL program. The optimum parameters were investigated by changing more than 10 initial values. Then, the metamodels were built, by setting the weight and reaction force as response values.

For the kriging models of weight and buckling load, their optimum parameters are summarized in Table 3 . These optimal parameters were used to find the optimum design of (3) (5), and as a result, $\left[\begin{array}{llll}x_{1}^{*} & x_{2}^{*} & x_{3}^{*} & x_{4}^{*}\end{array}\right]^{T}=\left[\begin{array}{lll}4.24^{\circ} & 2.39^{\circ}\end{array}\right.$ $11.29 \mathrm{~mm} 1.86 \mathrm{~mm}]^{T}$ was found, and the approximate weight and the approximate buckling load at the optimal solution were, respectively, $130.7 \mathrm{~g}$ and $27,205 \mathrm{~N}$. The true weight of the optimum design was $131.0 \mathrm{~g}$. The buckling analysis result represented as a force-displacement curve is shown in Figure 6(a). The true buckling load of the optimum design was calculated as $28,024 \mathrm{~N}$.

For the suggested optimum design, durability analysis for the unit of OTR was performed, to investigate the design requirement imposed on the OTR. The loading condition applying an equivalent load is represented as a sine curve. The loading condition and design criterion were supplied by car maker A. The fatigue life calculated from MSC Fatigue is shown in Figure 6(b). The fatigue life of the suggested optimum design was determined as 1,760 cycles, which satisfies the design requirement specified by car maker A. 


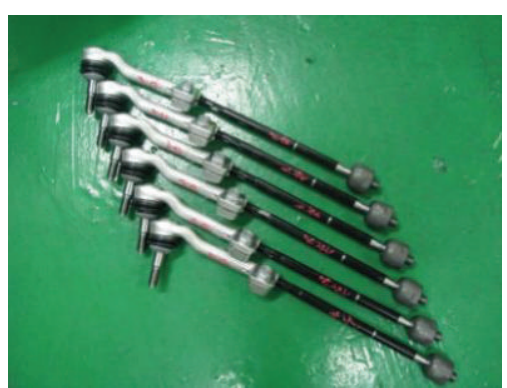

(a) Six specimens before test

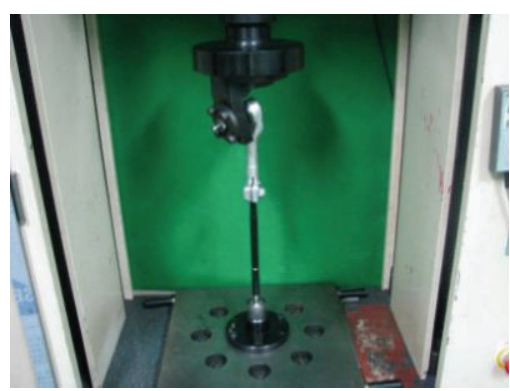

(b) Test equipment

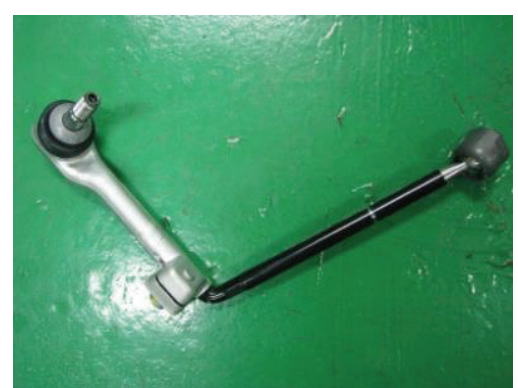

(c) One specimen after test

Figure 7: Buckling test result.

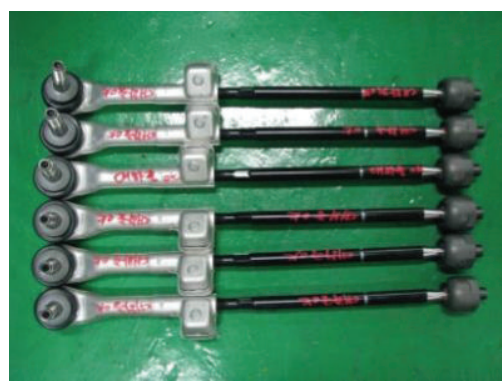

(a) Six specimens before test

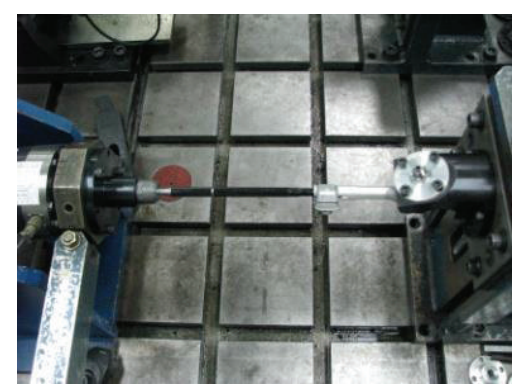

(b) Test equipment

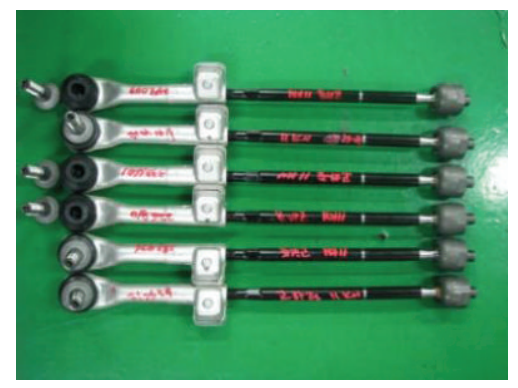

(c) Six specimens after test

FIGURE 8: Fatigue test result.

TABLE 3: Optimal parameters of kriging models.

\begin{tabular}{lccccc}
\hline Response & $\beta$ & $\theta_{1}$ & $\theta_{2}$ & $\theta_{3}$ & $\theta_{4}$ \\
\hline$W$ & $138.6 \mathrm{~kg}_{\mathrm{f}}$ & 0.004 & 20.54 & 4.74 & 10.33 \\
$F_{R}$ & $27,690 \mathrm{~N}$ & 0.001 & 5.07 & 18.90 & 50.00 \\
\hline
\end{tabular}

3.4. Buckling and Fatigue Tests. Based on the suggested optimum design, twelve specimens were made to validate the bucking and durability performance. For the buckling test, six specimens of the OTR connected with the ITR are shown in Figure 7(a). The test equipment is shown in Figure 7(b), in which the loading and boundary conditions are the same as those of the buckling analysis. As a result, the buckling loads were between $25,900 \sim 27,550 \mathrm{~N}$, and all of them satisfy the criterion. Comparing the average value obtained from six buckling loads, the simulation result has a relatively small error, of about $5 \%$. One specimen after the buckling test is shown in Figure 7(c).

For the durability test, six other specimens were prepared, as shown in Figure 8(a). The test equipment for the durability was set up as shown in Figure 8(b). Through the test, their fatigue lives were between 249,049 cycles and 312,659 cycles. Those results satisfy the requirement set by car maker A. It is found that the test results of the buckling and durability are consistent with those of the simulations.

\section{Conclusions}

The present research suggested an optimum design of Al6082M OTR, which is one of the parts of the steering system of an electrical vehicle. The following conclusions can be made from this study.

(1) The present research has succeeded in the development of a lightweight OTR, by replacing the current OTR, whose initial model was made of steel, with an Al6082M OTR, and applying the optimization technique. The metamodel-based optimization technique provides a realistic optimum, even though it cannot be considered as an exact solution. The weight of the suggested optimum design is $131.0 \mathrm{~g}$, which is $65.3 \%$ lighter weight than the initial steel model.

(2) It is proven that the design requirements related to the bucking and durability performance were satisfied through the tests. For the buckling test, six specimens were used, and their buckling loads were between $25,900 \sim 27,550 \mathrm{~N}$. In the case of the durability test, all the fatigue lives of the six specimens exceeded the allowable cycle.

\section{Conflict of Interests}

The authors declare that there is no conflict of interests regarding the publication of this paper.

\section{Acknowledgments}

This research was financially supported by the Ministry of Education Science and Technology (MEST) and the National Research Foundation of Korea (NRF), through 
the Human Resource Training Project for Regional Innovation (2012H1B8A2026078).

\section{References}

[1] Porsche Engineering Services Inc., "The design, materials, manufacturing, structural performance and economic analysis of the ultra light steel auto closures program," Engineering Report, 2000.

[2] K. H. Lee and D. H. Kang, "Structural optimization of an automotive door using the kriging interpolation method," Proceedings of the Institution of Mechanical Engineers D: Journal of Automobile Engineering, vol. 221, no. 12, pp. 1525-1534, 2007.

[3] B. C. Song, Y. C. Park, S. W. Kang, and K. H. Lee, "Structural optimization of an upper control arm, considering the strength," Proceedings of the Institution of Mechanical Engineers D: Journal of Automobile Engineering, vol. 223, no. 6, pp. 727-735, 2009.

[4] T. Bein, "Advanced design for electric cars," 2013, http://www. emrs-strasbourg.com/files/FALL\%202011/t.bein.pdf.

[5] J. K. Kim, Y. J. Kim, W. H. Yang, Y. C. Park, and K.-H. Lee, "Structural design of an outer tie rod for a passenger car," International Journal of Automotive Technology, vol. 12, no. 3, pp. 375381, 2011.

[6] B. K. Seo, S. K. Baek, Y. C. Park, and K. H. Lee, "Structural optimization of outer tie rod for electrical vehicle," in Proceedings of the International Symposium on Green Manufacturing and Applications, Honolulu, Hawaii, USA, June 2013.

[7] K. H. Lee and J. I. Heo, "Metamodel-based optimum design examples of structures," in Handbook of Research on Novel Soft Computing Intelligent Algorithms: Theory and Practical Applications, pp. 667-676, IGI Global.

[8] 2013, http://www.3ds.com/productsservices/catia.

[9] MSC Software, Linear Static Analysis User's Guide: MSC Nastran, 2012.

[10] MSC Software, MSC.fatigue version 2007 r2 user manual, 2008.

[11] Dassault Systèmes Simulia Software Corporation, ABAQUS 6.8.1 Documentation, Providence, RI, USA, 2008.

[12] J. Sacks, W. J. Welch, T. J. Mitchell, and H. P. Wynn, "Design and analysis of computer experiments," Statistical Science, vol. 4, no. 4, pp. 409-435, 1989.

[13] A. Guinta and L. Watson, "A comparison of approximation modeling techniques: polynomial versus interpolating models," in Proceedings of the 7th AIAA/USAF/NASA/ISSMO Symposium on Multidisciplinary Analysis and Optimization, vol. 2, pp. 392440, AIAA, St. Louis, Mo, USA.

[14] K. T. Fang, R. Li, and A. Sudjianto, Design and Modeling for Computer Experiments, Chapman \& Hall/CRC, London, UK, 2006. 


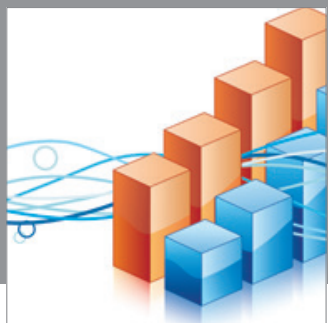

Advances in

Operations Research

mansans

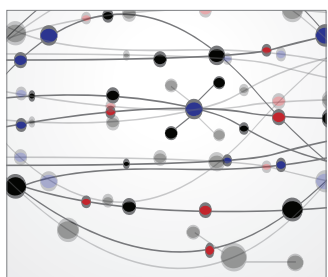

The Scientific World Journal
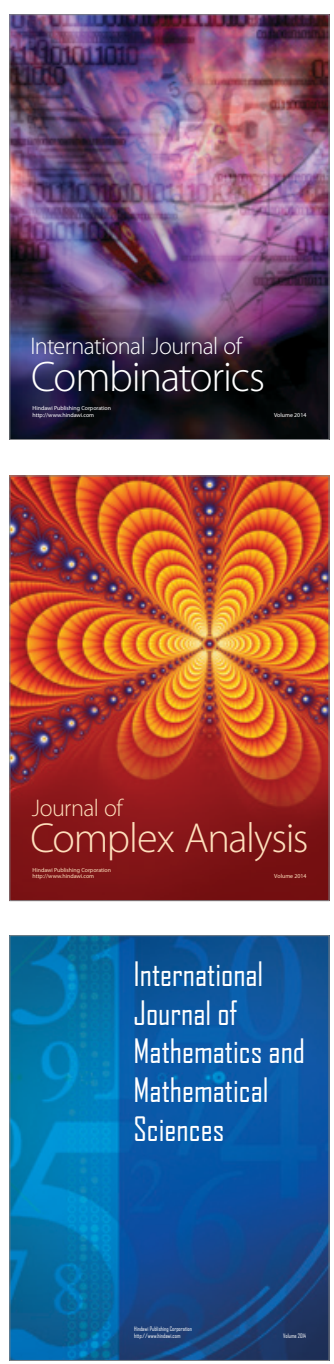
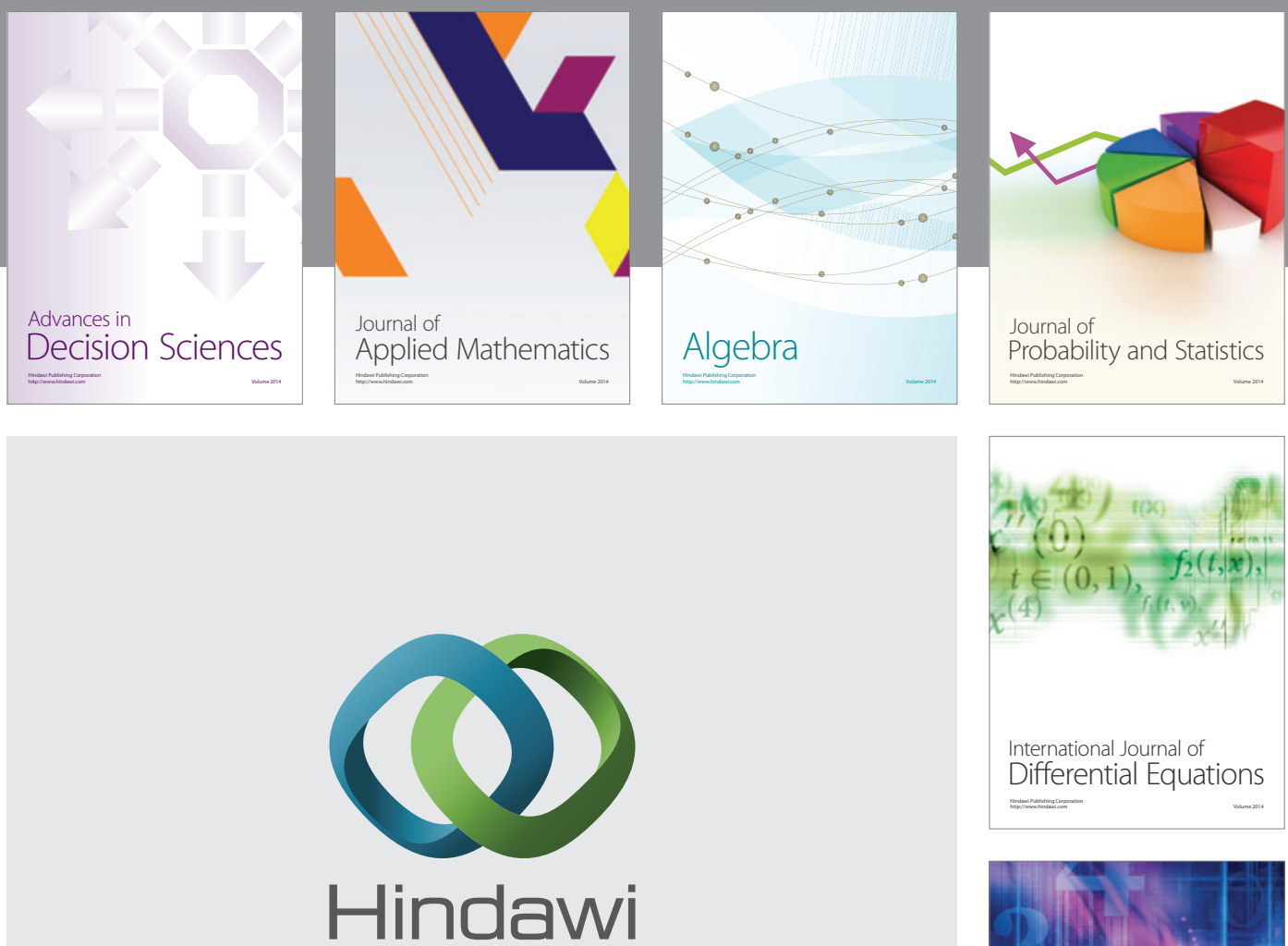

Submit your manuscripts at http://www.hindawi.com
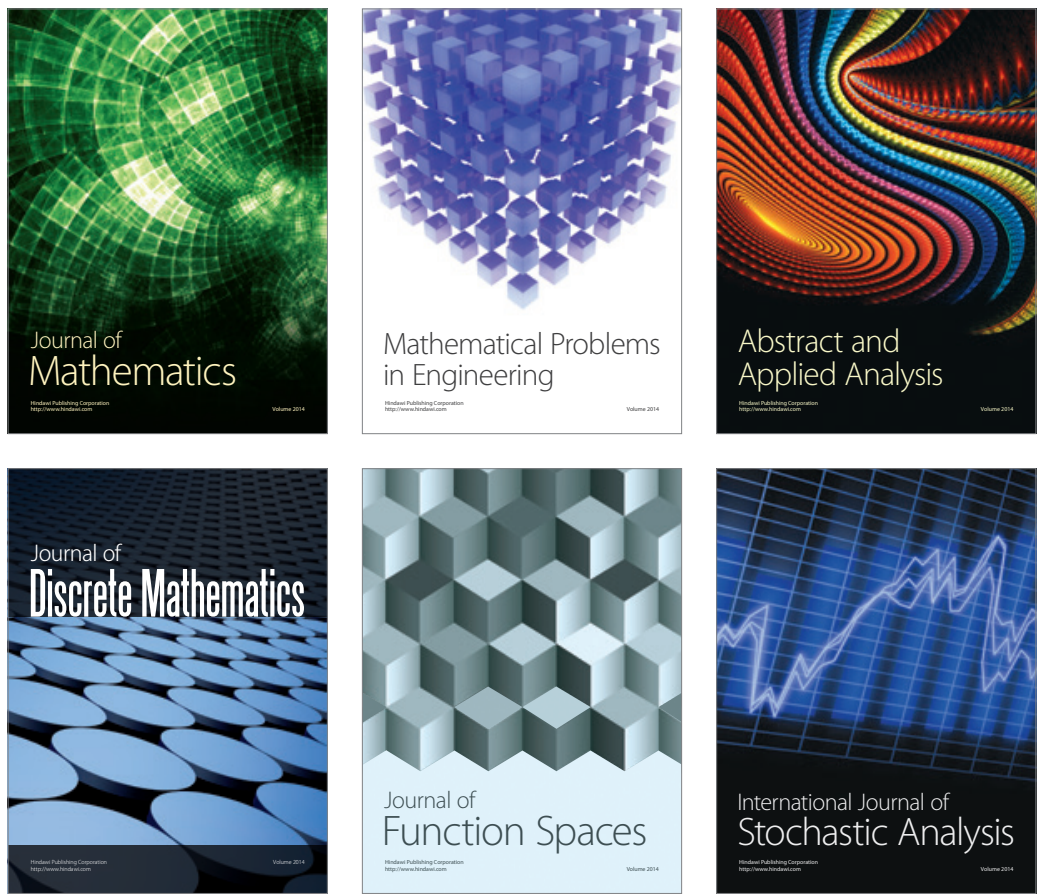

Journal of

Function Spaces

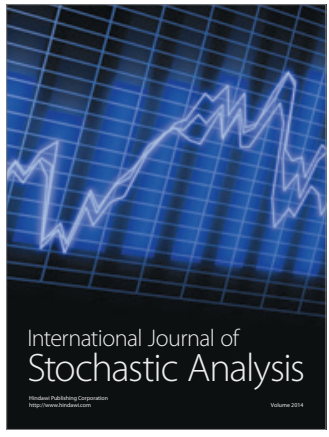

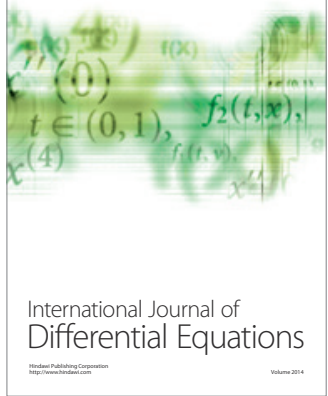
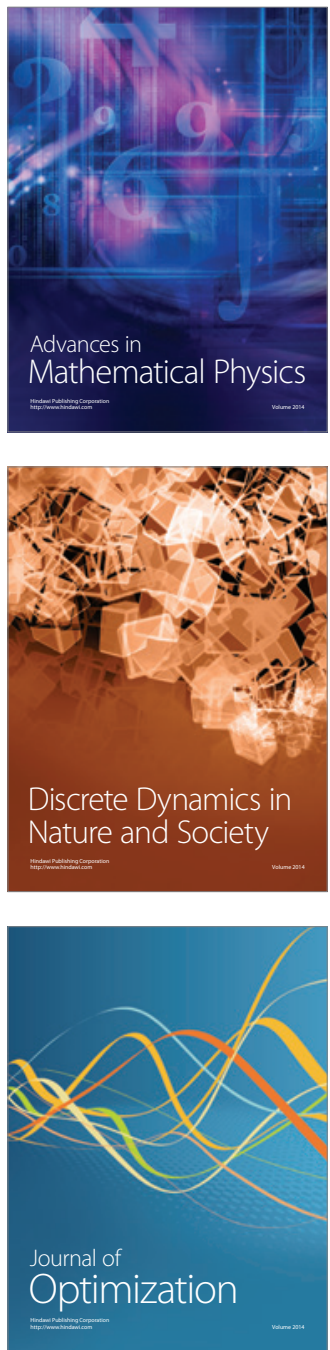